\title{
ENTREVISTA
}

\section{A REFORMA DO ENSINO MÉDIO}

\begin{abstract}
Lei n. 13.415/2017, promulgada em fevereiro deste ano, vinha sendo bastante aguardada e discutida por estudantes e profissionais da Educação em todo o país, desde a polêmica Medida Provisória n. 746, de 22 de setembro de 2016, que ampliou o debate sobre a composição curricular do ensino médio. A Lei n. 13.415/2017 institui a Política de Fomento à Implementação de Escolas de Ensino Médio em Tempo Integral - que entre outras mudanças, permitirá ao aluno cursar o ensino técnico dentro da carga horária do ensino regular, sem prejuízo de, em seguida, ir para o ensino superior. Veja, então, como o Ministério da Educação do Brasil se prepara para a Reforma do Ensino Médio.
\end{abstract}

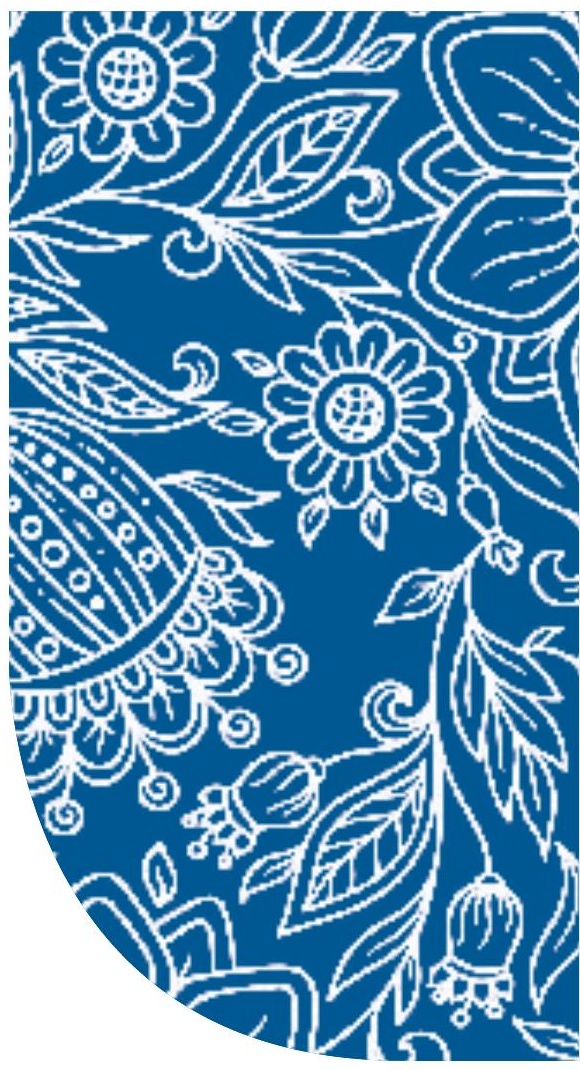




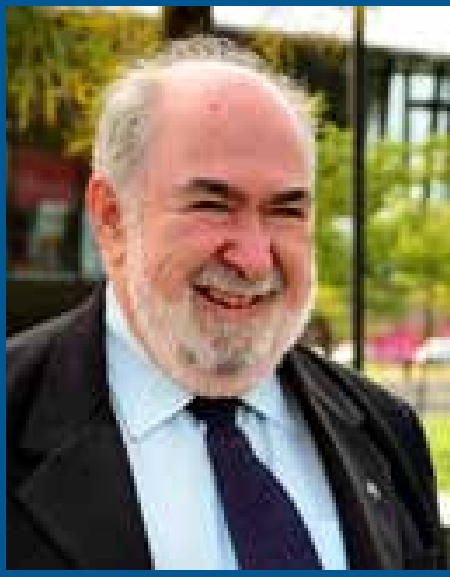

Professor Francisco Aparecido Cordão

Especialista em Educação Profissional. Titular da

Cadeira 28 da Academia

Paulista de Educação. Peabiru Educacional. São Paulo, São Paulo, Brasil.

facordao@uol.com.br

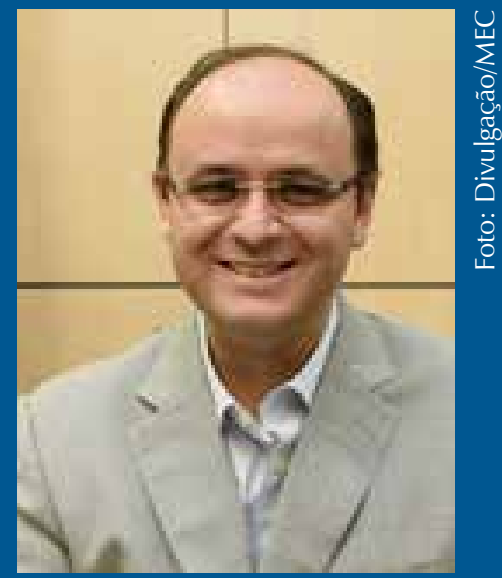

Rossieli Soares da Silva

Secretário de Educação Básica do Ministério da Educação e Conselheiro da Câmara de Educação Básica do Conselho Nacional de Educação. Brasília, Distrito Federal, Brasil.

rossielisilva@mec.gov.br 
Francisco Aparecido Cordão - O Senhor era Secretário Estadual de Educação do Amazonas, quando o Conselho Nacional de Secretários de Educação (Consed) organizou, em Manaus, um grande debate sobre o Projeto de Lei (PL) n. 6.840/2013, em tramitação na Câmara dos Deputados, sob responsabilidade dos Deputados Reginaldo Lopes e Wilson Filho. O Consed chegou a oferecer importantes contribuições àquele Projeto de Lei, objetivando alterar significativamente as condições de oferta do Ensino Médio no Brasil, considerando, especialmente, a qualidade atual da oferta dessa etapa de ensino, se analisados os resultados de avaliação obtidos no âmbito do Sistema Nacional de Avaliação da Educação Básica (Saeb) e do Programme for International Student Assessment (Pisa). Quais foram as principais contribuições do Consed para o aprimoramento do PL n. $6.840 / 2013$ e quais as principais discordâncias?

Prof. Dr. Rossieli Soares da Silva - Em junho de 2015, o Consed reformulou o Grupo de Trabalho (GT) de Reforma do Ensino Médio, do qual fui o coordenador. Este grupo de trabalho foi responsável pela assessoria técnica nas discussões relativas ao Ensino Médio, na interlocução com o MEC e outros órgãos afetos a políticas, programas e projetos do segmento.

Em junho, setembro e novembro de 2015, o GT de Reformulação do Ensino Médio realizou encontros em Brasília, Mato Grosso do Sul e Manaus, respectivamente. Coordenadores do ensino médio das Secretarias Estaduais de Educação de todo o Brasil tiveram efetiva participação neste GT, que contou com a assessoria de especialistas no assunto.

Paralelamente, videoconferências sobre a reformulação do ensino médio foram realizadas com os coordenadores do projeto nas Secretarias Estaduais de Educação, via Centro de Mídias de Educação do Amazonas.

A partir destes encontros, um documento foi redigido - a "Carta de Princípios sobre o Ensino Médio Brasileiro", contendo o posicionamento sobre a Base Nacional Comum Curricular (BNCC) e proposições em relação ao PL n. 6.840/2013. Este documento foi entregue, em 3 de março de 2016, ao Ministério da Educação, pelos Secretários Estaduais de Educação de todo o Brasil, por meio do Consed.

O PL n. 6.840/2013 teve autoria do deputado federal Reginaldo Lopes, do Partido dos Trabalhadores (PT), e a "Carta de Princípios sobre o Ensino Médio Brasileiro", fruto de todas as discussões do GT do Consed, trouxe aprimoramentos com base na experiência de gestão dos secretários estaduais de educação, como no caso da obrigatoriedade da Língua Inglesa enquanto língua estrangeira; a inclusão da ênfase em formação técnica e profissional juntamente com as áreas de conhecimento - Linguagens e suas Tecnologias, Matemática e suas Tecnologias, Ciências da Natureza e 
suas Tecnologias e Ciências Humanas e Sociais Aplicadas - e concomitante ao ensino médio; além da exclusão do quarto ano para o ensino médio noturno.

Francisco Aparecido Cordão - Na atual composição do Ministério da Educação, o senhor assumiu a condução da Secretaria de Educação Básica do Ministério, que adotou como uma de suas metas prioritárias a reforma do ensino médio, considerando que o mesmo não estava atendendo aos anseios das juventudes. Para concretizar essa prioridade, o MEC adotou uma opção considerada radical, encaminhando ao Congresso Nacional a Medida Provisória (MP) n. 746, de 22 de setembro de 2016. Por que a adoção de uma Medida Provisória, e não a de incentivo ao Congresso Nacional para concluir rapidamente os debates em andamento e aprovar a Reforma do Ensino Médio, que estava em processo?

Prof. Dr. Rossieli Soares da Silva - O MEC compreende que o processo de discussão da MP 746/2016, em uma perspectiva democrática, conseguiu, de forma efetiva e legítima, contribuições dos diferentes atores. Desta forma, respeitou todo o debate ocorrido ao longo de, pelo menos, 20 anos. A Reforma do Ensino Médio é fruto do amplo debate acumulado no País nas últimas décadas, o que permitiu ao governo acelerá-la:

- 1998: grande debate e aprovação das Diretrizes do Ensino Médio de acordo com a nova Lei de Diretrizes e Bases da Educação Nacional (LDB), de 1996;

- 2002: seminário nacional sobre Reforma do Ensino Médio;

- 2007: Fundo Nacional de Manutenção e Desenvolvimento da Educação Básica e de Valorização dos Profissionais da Educação (Fundeb), com a promessa de garantir a universalização do EM;

- 2007: MEC lança o Plano de Ações Articuladas;

- 2009: Novo Exame Nacional do Ensino Médio (Enem);

- 2010: Ensino Médio Inovador;

- 2010: Consed cria o Grupo de Trabalho de Reforma do Ensino Médio;

- 2012: Diretrizes Curriculares Nacionais para o Ensino Médio aprovadas pelo Conselho Nacional de Educação (CNE);

- 2013: Projeto de Lei n. 6.840/2013; 
- 2014: Plano Nacional da Educação (PNE). Meta 3.1 “Institucionalizar programa nacional de renovação do ensino médio, a fim de incentivar práticas pedagógicas com abordagens interdisciplinares estruturadas pela relação entre teoria e prática, por meio de currículos escolares que organizem, de maneira flexível e diversificada, conteúdos obrigatórios e eletivos articulados..."

Francisco Aparecido Cordão - Julgo que a Medida Provisória n. 746/2016, de imediato, teve como mérito colocar o ensino médio na pauta nacional do noticiário. Para o bem e para o mal, ninguém ficou indiferente em relação a essa temática. Verifica-se, analisando a tramitação da MP n. 746/2016 no Congresso Nacional, que foram realizadas dezenas de audiências públicas nacionais, especialmente, atendendo a requerimentos dos congressistas. Qual foi a contribuição dessas audiências públicas?

Prof. Dr. Rossieli Soares da Silva - As audiências públicas foram a culminância do processo de debates ocorridos, como já disse, nos últimos 20 anos, e que ganhou fôlego recente, em 2013, com o PL n. 6.840, sendo, então, a Reforma abraçada pelos gestores desse segmento de ensino - o Consed -, em 2015, com a renovação do GT de reformulação dessa etapa da Educação Básica.

Estas audiências foram extremamente contributivas, no sentido de terem rememorado todo esse processo de debate e, principalmente, por terem trazido a clareza necessária sobre a urgência e relevância da Reforma, pela qual podemos deixar claro que ensino médio é a modalidade de ensino que apresenta, hoje em dia, os piores resultados e aspectos mais desafiadores do sistema educacional brasileiro.

Francisco Aparecido Cordão - A temática da MP n. 746/2016 mantém interface direta com a Base Nacional Comum Curricular da Educação Básica, em todas as suas etapas e modalidades de ensino, sendo objeto de amplo debate nacional, com efetiva participação de professores e especialistas. De certa maneira, a proposta curricular apresentada pela MP n. 746/2016 não acabou atropelando esse debate em relação ao ensino médio? Ou ela contribuiu para melhor qualificar essa discussão?

Prof. Dr. Rossieli Soares da Silva - Já imaginou o que seria formular uma Base Nacional Comum Curricular (BNCC) do Ensino Médio, no modelo de trajetória que estava vigente no Brasil, com 13 disciplinas obrigatórias para todos, em todos os anos, sem nenhuma possibilidade de escolha pelo aluno?

Não havia mais condições de termos perspectivas de futuro para os jovens do nosso País, caso não realizássemos esta reforma. E a BNCC precisa ser 
elaborada a partir do desenho do novo modelo, indicando as competências e os objetivos de aprendizagem por área de conhecimento.

Neste contexto, o MEC entende que a Base Nacional Comum Curricular do Ensino Médio deve ser elaborada a partir do desenho desta Reforma. A análise realizada junto a especialistas que elaboraram os currículos na Austrália, nos Estados Unidos e na Inglaterra apontam a defasagem que a primeira versão da BNCC do ensino médio representa em relação ao resto do mundo, porque referendava o modelo falido. Os mesmos especialistas também apontam para o fato de que, em todo mundo, as propostas de BNCC envolvem um modelo. Não há como ter uma BNCC sem um modelo.

Francisco Aparecido Cordão - O novo currículo do ensino médio, composto pela BNCC e por itinerários formativos organizados por meio da oferta de diferentes arranjos curriculares, inegavelmente, representa um grande avanço na reforma do ensino nessa etapa de conclusão da educação básica. Como as escolas públicas de ensino médio terão condições de concretizar essa inovação em conformidade com a relevância para o respectivo contexto local e as reais possibilidades de seus sistemas de ensino?

Prof. Dr. Rossieli Soares da Silva - Temos um prazo para a execução do projeto. Os sistemas de ensino deverão estabelecer cronograma de implantação das principais alterações legislativas promulgadas, no primeiro ano letivo subsequente à data de publicação da BNCC, e iniciar o processo de implementação, conforme o referido cronograma, a partir do segundo ano letivo.

No início do ano letivo de 2016, quando exercia o cargo de Secretário de Educação do Amazonas, iniciei um projeto-piloto com proposta de currículo diferenciada para as 22 escolas de ensino médio com os piores indicadores educacionais em Manaus. A ideia era oferecer cursos na vertente acadêmica, na vertente técnico-profissional ou em ambas, para obtermos resultados inovando na oferta do ensino.

O modelo do novo ensino médio oferece muitas possibilidades. Quando afirmamos que este modelo dialoga muito mais com a realidade do estudante, isto também é certo para o sistema de ensino. As escolas poderão organizar o ensino em módulos ou créditos, por exemplo.

Portanto, para a implementação deste modelo, a maior mudança é de paradigma. À medida que modernizarmos a educação brasileira, igual a este primeiro passo que demos com o novo ensino médio, vamos ter o fruto disso, que serão jovens muito mais preparados para seus projetos de vida. 
O objetivo é tornar a escola de ensino médio mais atraente e articulada com o mundo em que vivemos.

Francisco Aparecido Cordão - O CNE definiu, desde o primeiro momento, suas Diretrizes Curriculares Nacionais para o Ensino Médio por áreas do conhecimento e suas tecnologias. A concretização dessas diretrizes, entretanto, tem encontrado resistência por parte dos executores dessa política educacional. O fato de a centralidade dessas áreas do conhecimento e suas tecnologias ser apresentada pela MP n. 746/2016 com foco nos itinerários formativos facilitará a concretização desta proposta?

Prof. Dr. Rossieli Soares da Silva - Com base na experiência do GT de Reformulação do Ensino Médio do Consed e na continuidade de sua condução pelos atuais gestores, desconheço essa resistência.

Francisco Aparecido Cordão - Na qualidade de Ex-secretário Estadual de Educação e atual Secretário de Educação Básica do MEC e Conselheiro da Câmara de Educação Básica do CNE, como imagina que os sistemas de ensino definirão critérios para a organização dessas áreas curriculares e seus itinerários formativos em relação às respectivas competências e habilidades? O que o MEC pretende fazer para articular os diferentes sistemas de ensino na execução dessa importante tarefa?

Prof. Dr. Rossieli Soares da Silva - O MEC, o CNE, os Conselhos Estaduais de Educação e os gestores das redes de ensino deverão avaliar as condições necessárias para a oferta dos diferentes itinerários e definir como será realizada a distribuição da oferta. Ressaltamos que, além de ofertar os diferentes itinerários formativos, a nova legislação possibilitará ao estudante cursar mais de um itinerário.

As redes de ensino deverão analisar o contexto social das diversas regiões que compõem sua Unidade Federativa e, em conjunto com as comunidades escolares, definir quais serão os itinerários formativos que serão ofertados em cada uma das diferentes unidades escolares.

Francisco Aparecido Cordão - A inclusão da oferta da formação técnica e profissional como um dos itinerários formativos integrantes da nova organização curricular, por meio da oferta de diferentes arranjos curriculares para o ensino médio, inegavelmente, representa um avanço na concretização do mandamento constitucional (Art. 205) e da LDB (Art. 2º) para garantir o cumprimento da finalidade da educação básica, em termos de "pleno desenvolvimento do educando, seu preparo para o exercício da cidadania e sua qualificação para o trabalho". Esse dispositivo representa notório avanço, entretanto, sua concretização exigirá, necessariamente, a adoção do 
regime de parcerias com outras instituições educacionais e organizações do trabalho. Como esse esforço será incentivado e organizado?

Prof. Dr. Rossieli Soares da Silva - A educação profissional é um dos possíveis itinerários formativos que o estudante poderá seguir e poderá ocorrer na própria escola estadual ou em escolas conveniadas, como o Serviço Social da Indústria (Sesi) e o Serviço Nacional de Aprendizagem Industrial (Senai), ou ainda, a distância, também por meio de convênios. Não é preciso integrar modelos, e sim, ampliá-los.

Francisco Aparecido Cordão - Formação de professores e demais profissionais da Educação para atender essa nova demanda, em especial, no que se refere à educação técnica e profissional, representa o grande gargalo na aplicação da Lei n. 13.415/2017? Como MEC e CNE organizarão uma política de articulação com os órgãos normativos e executivos dos diferentes sistemas de ensino para concretizar essa avançada proposta pedagógica em relação aos condutores de sua execução no âmbito das instituições educacionais?

Prof. Dr. Rossieli Soares da Silva - Os cursos de formação de professores terão prazo de dois anos a partir da publicação da BNCC para incorporá-la aos seus currículos.

A implementação do novo ensino médio depende da publicação da BNCC pelo CNE e sua homologação pelo MEC. Após essa etapa crucial, os estados precisarão adequar seus currículos à BNCC. A ampliação da carga horária será outro grande desafio para as redes de ensino. O governo federal tem dois programas que contribuem com os estados nessa ampliação: o Ensino Médio Inovador e o Fomento às Escolas em Tempo Integral. Estes programas apoiam não só a ampliação do tempo, como também o outro pilar da Reforma, que é a flexibilização do currículo. Permitir que os alunos trilhem diferentes itinerários formativos, de acordo com seus interesses, em uma mesma escola, requer repensar a organização dessa escola.

Assim, estudos e diagnósticos precisam ser realizados por todos os estados e o Distrito Federal, para que os mesmos possam ter, de forma clara, informações sobre a condição atual de cada um para a implementação da flexibilidade, com diversificação das propostas que poderão ser ofertadas.

É importante, também, que os estados organizem, com as escolas, consultas junto aos estudantes e professores para identificar as demandas, os interesses dos jovens, as competências e a disponibilidade dos professores.

Sabemos de estados que já possuem experiências de incorporar parte da proposta que está presente na reformulação do ensino médio e a ideia 
é que possamos trabalhar com eles, fortalecendo a parceria e a troca de experiências.

Francisco Aparecido Cordão - O que mais julga importante informar aos leitores do Boletim Técnico do Senac - a Revista de Educação Profissional sobre esta importante decisão do Governo Federal em relação à aplicação dos dispositivos da Lei n. 13.415/2017, de conversão da Medida Provisória n. $746 / 2016$ ?

Prof. Dr. Rossieli Soares da Silva - Quero salientar que a inclusão do curso técnico no currículo do ensino médio permitirá que o jovem tenha mais essa opção de se qualificar para uma profissão no mesmo espaço de tempo que levaria para concluir o ensino médio.

Atualmente, se o jovem quiser cursar uma formação técnica de nível médio, ele precisa cursar, no mínimo, 2.400 horas do ensino médio regular e mais 1.200 horas do técnico. O Novo Ensino Médio permitirá que o jovem opte por uma formação técnica profissional dentro da carga horária do ensino médio regular. E, no fim dos três anos, os sistemas de ensino deverão certificá-lo no ensino médio e no curso técnico cursado.

Essa maior ligação com o mundo do trabalho torna o ensino médio mais atrativo para o jovem que precisa trabalhar, sem impedir que ele, posteriormente, curse também o ensino superior. 